\title{
Ugi post-condensation copper-triggered oxidative cascade towards pyrazoles
}

\author{
Aurélie Dos Santos, Laurent El Kaim*, Laurence Grimaud \\ and Caroline Ronsseray
}

\section{Letter}

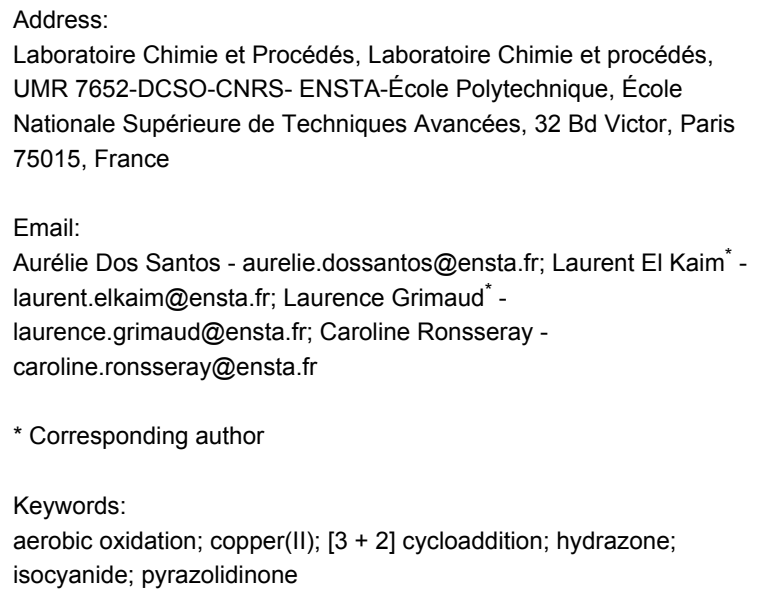

\begin{abstract}
\section{Introduction}

In the last twenty years, the Ugi reaction coupled with its various post-condensations towards heterocyclic libraries has established the success of isocyanide-based multicomponent reactions [1-7]. Chemists in both academia and industry have taken advantage of the functional group tolerance of the Ugi coupling to apply to these adducts the various cyclizations offered by the chemists toolkit. We became involved in the Ugipost-condensation field through our initial interest in radical processes. We found that, compared with classical cycloadditions, cyclocondensations and organometalic couplings, there was no existing description of radical processes on such
\end{abstract}

Pyrazolidinones were prepared in a two-step sequence starting from $\alpha$-hydrazonocarboxylic acids. After a four-component Ugi coupling, the resulting hydrazone was engaged in a copper triggered [3+2] cycloaddition/aerobic oxidation cascade.

adducts. Thus, we decided to undertake various studies using xanthate transfer [8-10], Mn(III) or copper(II) triggered oxidative couplings $[11,12]$.

We recently reported a new synthesis of fused pyrazolidinone under oxidative conditions from simple hydrazone derivatives (Scheme 1) [13]. The cascade features a [3+2] cycloaddition coupled with an aerobic oxidation of the resulting pyrazolidine. A further oxidative coupling may be observed according to the substitution pattern of the starting acyl chloride. Considering our interest in IMCR, we envisioned that a similar cascade 
could be performed on a properly functionalized Ugi adduct allowing us to reach a new 4-component access to pyrazole derivatives. The present letter summarizes our efforts in this direction.

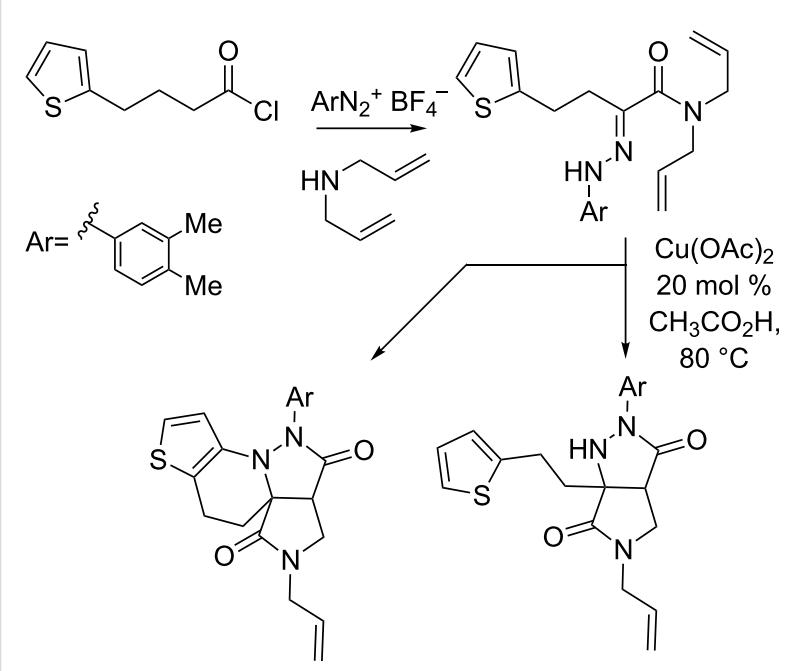

Scheme 1: Copper-catalyzed oxidative cyclization of alkenyl hydrazone.

\section{Results and Discussion}

Among the possible Ugi pathways to introduce an alkene moiety that is prone to undergo an intramolecular [3+2] cycloaddition with a hydrazone, we selected the Ugi coupling between $\alpha$-hydrazonocarboxylic acids and allylamine as the most straightforward path. There are several reports on the use of hydrazones in Ugi reactions [14-23], however, to the best of our knowledge, there is no report involving $\alpha$-hydrazonocarboxylic acids.

Hydrazone 1a was prepared through condensation of pyruvic acid with phenylhydrazine. Adding 1a to aqueous formaldehyde, allylamine and tert-butylisocyanide in $\mathrm{MeOH}$ under standard Ugi conditions, led to the formation of the amide 2a in $64 \%$ isolated yield. The compatibility of the hydrazone with this coupling is certainly due to the higher electrophilicity of the intermediate iminium. The latter traps the isocyanide before any interaction with the hydrazone. The first attempted oxidative cyclization of $\mathbf{2 a}$ was made with one equivalent of copper acetate in acetic acid as solvent and gave the expected pyrazolidinone $\mathbf{3 a}$ in a $57 \%$ isolated yield (Scheme 2, condition A). Based on our previous study, the yield was improved to reach $84 \%$ with a mixture of acetic acid and water (80/20). A combination of DMF, acetic acid and water allowed us to optimize this reaction working with a reduced $20 \mathrm{~mol} \%$ of copper ( $84 \%$ isolated yield, Scheme 2 , condition D). The reaction was performed at $80^{\circ} \mathrm{C}$, overnight, and under argon. We believe that under these conditions a slow uptake of oxygen helps to control the selective oxidation process. Reactions performed under air were faster but led to intractable mixtures.

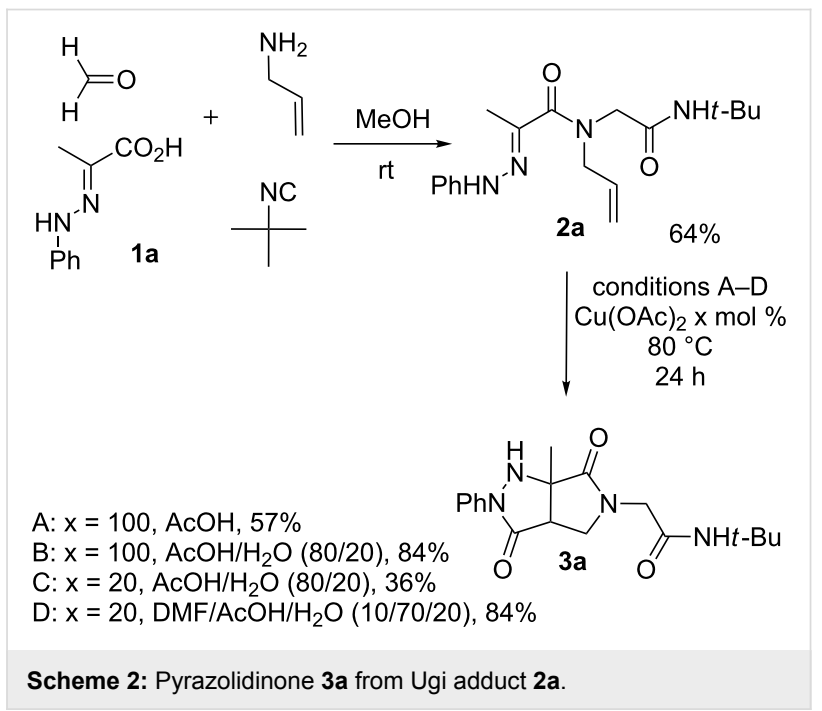

Analogous hydrazones prepared from pyruvic acid and benzoylformic acid with hydrazine derivatives were tested in this Ugi/ oxidative cyclization sequence under these optimized conditions. Results are reported in Table 1. Surprisingly, the reaction appears to be only efficient with Ugi adducts prepared with formaldehyde as the carbonyl component (Table 1, entries 1-5). With other aldehydes and ketones, even if the Ugi reaction was performed easily, the following cyclization failed to give the expected pyrazolidinones and resulted in complex mixture formation. Intermediate Ugi adduct $\mathbf{3 g}$ (Table 1, entry 6) only resulted in a small amount of ring-opened product $\mathbf{4 g}$. The reaction is also limited to $N$-aryl hydrazones due to the lower efficiency of the Ugi reaction with $\mathrm{N}$-alkyl hydrazones: An attempt of Ugi coupling with hydrazone 1d, formaldehyde, allylamine and tert-butylisocyanide failed to give any isolable adduct (Scheme 3). This may be explained by an enhanced nucleophilicity of the $\mathrm{N}$-monoalkyl hydrazone leading to a competition between the hydrazone and the amine component in the Ugi steps.

In order to gain further insight into the reactivity of $N$-alkyl derivatives, we decided to synthesize an initial hydrazone by a more conventional route. Benzoylformic acid was converted into its $N$-diallyl amide derivative. The latter failed to produce a hydrazone with methylhydrazine under standard conditions (EtOH, toluene, rt to reflux, with or without added acetic acid). However, we were able to trigger the addition under microwave conditions (in $\mathrm{EtOH}$ with 1.5 equiv of $\mathrm{AcOH}$ ). The expected hydrazone was still not synthesized, however, the cycloadduct 6 
Table 1: Cycloaddition/oxidation cascade from Ugi hydrazone adducts.

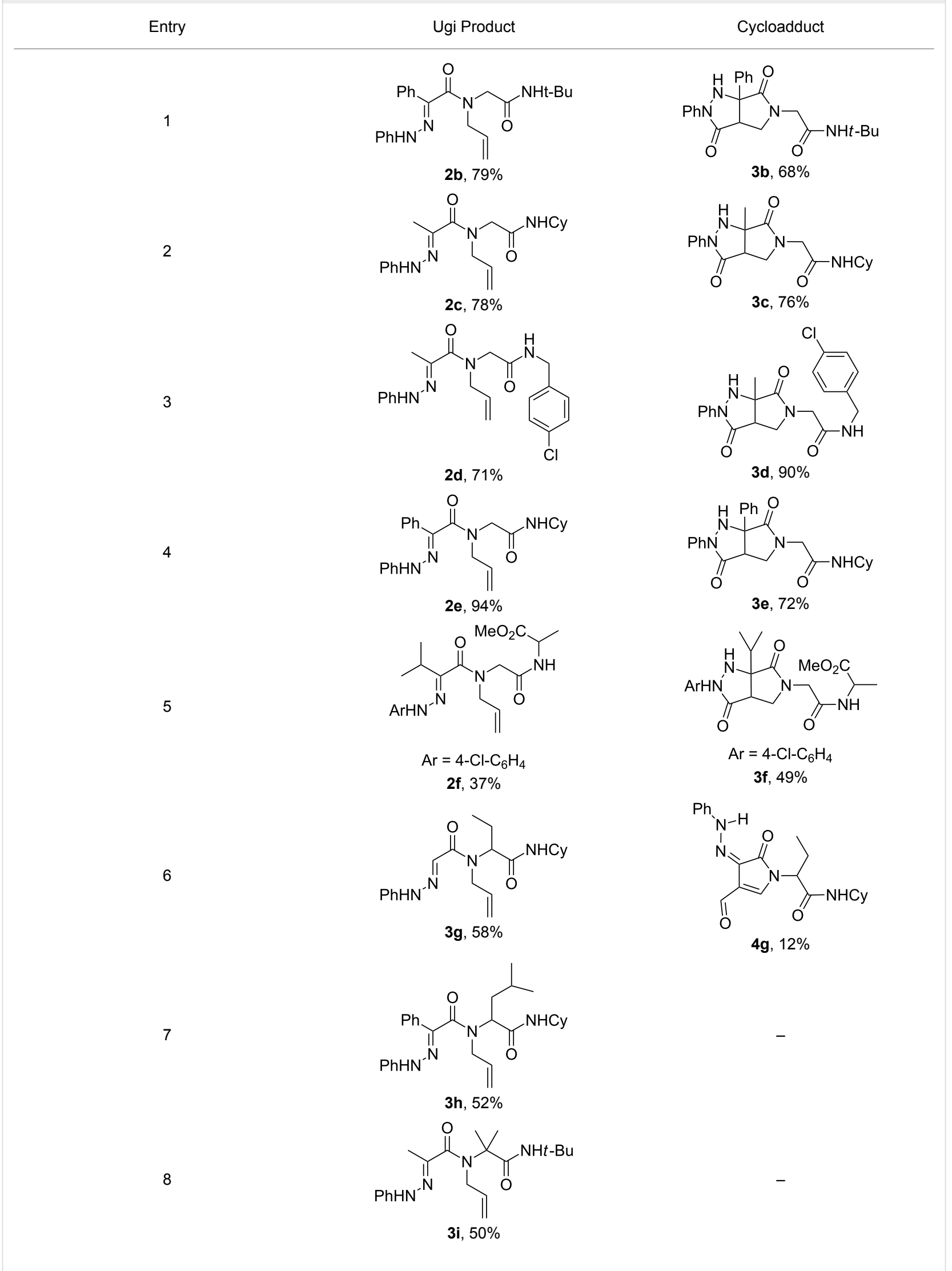




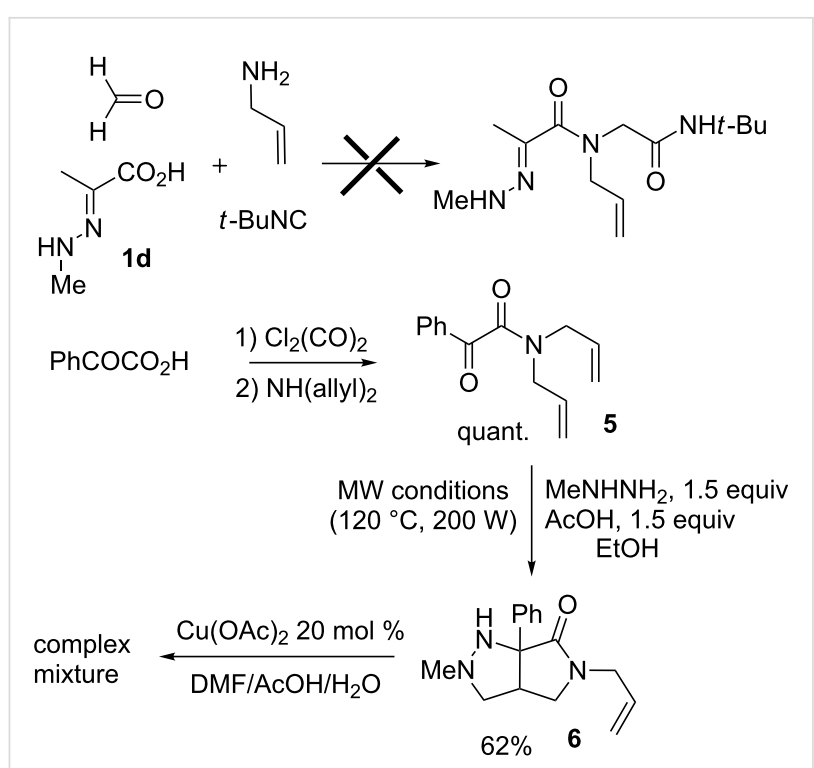

Scheme 3: Attempted reactions of $\mathrm{N}$-methyl hydrazones.

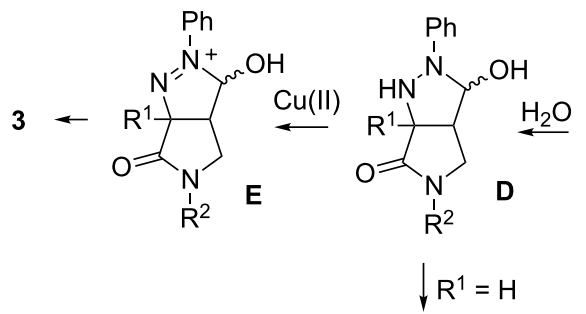<smiles>[R2]N1C=C(C=O)C(=NNc2ccccc2)C1=O</smiles><smiles>[R]N1C[C@H](C(=O)NF)[C@H](NC)C1=O</smiles>

Scheme 4: Proposed mechanism.

was obtained, probably through a $[3+2]$ cycloaddition triggered by acetic acid. The attempted oxidation of $\mathbf{6}$ with copper acetate in $\mathrm{DMF} / \mathrm{AcOH} / \mathrm{H}_{2} \mathrm{O}$ gave only complex mixtures.

The oxidation sequence may be explained by the mechanism depicted in Scheme 4 . The process starts with a $[3+2]$ cyclo- addition triggered either by copper acetate or acetic acid [2429]. The resulting pyrazoline A may be oxidized by copper(II) salts forming intermediate $\mathbf{D}$ after addition of water [30,31]. Two alternative paths may then be observed from D: Ringopening leading to azo or hydrazono derivatives such as $\mathbf{4 g}$, further oxidation without ring-opening giving the fused pyrazolidinone 3 .

\section{Conclusion}

In conclusion, we have disclosed a new Ugi coupling with $\alpha$-hydrazonocarboxylic acids. These Ugi adducts have been used in an Ugi post-condensation involving a [3+2] cycloaddition followed by an oxidative cascade. Among potential Ugi post-condensations, radical and oxidative processes represent a very promising route towards the formation of complex scaffolds. We are currently exploring the reactivity of the $N$-aryl Ugi-Smiles adducts using similar strategies.

\section{Experimental}

Typical procedure for the first step: $(E)-N$-allyl- $N$-(2-(tertbutylamino)-2-oxoethyl)-2-(2-phenylhydrazono)propanamide (2a): To a solution of formaldehyde $(210 \mu \mathrm{L}, 2.8 \mathrm{mmol})$ in methanol $(1 \mathrm{M})$ were added successively allylamine $(210 \mu \mathrm{L}$, $2.8 \mathrm{mmol}$ ), 2-(2-phenylhydrazono)propanoic acid (500 $\mathrm{mg}$, $2.8 \mathrm{mmol}$ ), and tert-butylisocyanide (230 $\mathrm{mg}, 2.8 \mathrm{mmol})$. The resulting mixture was stirred at $40{ }^{\circ} \mathrm{C}$ until completion of the reaction (TLC). The solvent was removed under reduced pressure. The product was isolated by flash chromatography on silica gel $\left(\mathrm{PE} / \mathrm{Et}_{2} \mathrm{O}\right)$ with a yield of $64 \% .{ }^{1} \mathrm{H} \mathrm{NMR}\left(\mathrm{CDCl}_{3}\right.$, $400 \mathrm{MHz}) \delta 7.52$ (br s, 1H), 7.29 (dd, $J=7.8,7.3 \mathrm{~Hz}, 2 \mathrm{H}), 7.09$ $(\mathrm{d}, J=7.8 \mathrm{~Hz}, 2 \mathrm{H}), 6.95(\mathrm{t}, J=7.3 \mathrm{~Hz}, 1 \mathrm{H}), 6.16($ br s, $1 \mathrm{H})$, 5.96-5.88 (m, 1H), 5.28-5.23 (m, 2H), 4.34-4.00 (m, 4H), 2.14 $(\mathrm{s}, 3 \mathrm{H}), 1.35(\mathrm{~s}, 9 \mathrm{H}) ;{ }^{13} \mathrm{C} \mathrm{NMR}\left(\mathrm{CDCl}_{3}, 100.6 \mathrm{MHz}\right) \delta 168.7$, 168.6, 143.9, 136.9, 132.8, 129.8, 122.0, 119.0, 114.0, 53.9, $51.7,51.3,29.1,12.6$.

Typical procedure for the oxidative cyclization: $N$-tertbutyl-2-(6a-methyl-3,6-dioxo-2-phenylhexahydropyrrolo[3,4-c]pyrazol-5(1H)-yl)acetamide (3a): To a solution of hydrazone 2 a $(100 \mathrm{mg}, 0.3 \mathrm{mmol})$ in a $10 / 70 / 20 \mathrm{DMF} /$ $\mathrm{CH}_{3} \mathrm{COOH} / \mathrm{H}_{2} \mathrm{O}$ mixture $(0.06 \mathrm{M})$ was added $\mathrm{Cu}(\mathrm{OAc})_{2}$ (20 mol \%). The resulting mixture was heated at $80{ }^{\circ} \mathrm{C}$ under argon. The $\mathrm{pH}$ was adjusted to 6 with an aqueous sodium hydrogencarbonate solution, and the aqueous phase was extracted with AcOEt. Then the organic layers were washed ten times with water, dried over anhydrous $\mathrm{MgSO}_{4}$, filtered and concentrated in vacuo. The product was isolated by flash chromatography on silica gel (PE/Et ${ }_{2} \mathrm{O}$ with $1 \%$ of TEA) with a yield of $84 \%$. ${ }^{1} \mathrm{H} \mathrm{NMR}\left(\mathrm{CDCl}_{3}, 400 \mathrm{MHz}\right) \delta 7.83(\mathrm{~d}, J=$ $8.3 \mathrm{~Hz}, 2 \mathrm{H}), 7.37(\mathrm{dd}, J=8.3,7.3 \mathrm{~Hz}, 2 \mathrm{H}), 7.17(\mathrm{t}, J=7.3 \mathrm{~Hz}$, 1H), 5.52 (br s, 1H, NH), 4.89 (br s, 1H), 3.93 (d, $J=16.2 \mathrm{~Hz}$, 
$1 \mathrm{H}), 3.85(\mathrm{dd}, J=10.3,6.3 \mathrm{~Hz}, 1 \mathrm{H}), 3.80(\mathrm{~d}, J=16.2 \mathrm{~Hz}, 1 \mathrm{H})$, $3.76(\mathrm{~d}, J=10.3 \mathrm{~Hz}, 1 \mathrm{H}), 3.22(\mathrm{~d}, J=6.3 \mathrm{~Hz}, 1 \mathrm{H}), 1.63(\mathrm{~s}$, $3 \mathrm{H}), 1.25(\mathrm{~s}, 9 \mathrm{H}) ;{ }^{13} \mathrm{C} \mathrm{NMR}\left(\mathrm{CDCl}_{3}, 100.6 \mathrm{MHz}\right) \delta 174.6$, 169.8, 166.3, 138.1, 129.2, 125.8, 119.5, 63.7, 52.0, 48.0, 47.6, 29.0, 18.9.

\section{Supporting Information}

\section{Supporting Information File 1}

Experimental procedures with characterization data for all new compounds.

[http://www.beilstein-journals.org/bjoc/content/ supplementary/1860-5397-7-153-S1.pdf]

\section{Acknowledgements}

We thank the ENSTA for financial support and C.R. thanks the École Polytechnique for fellowship.

\section{References}

1. Zhu, J.; Bienaymé, H., Eds. Multicomponent reactions; Wiley-VCH: Weinheim, Germany, 2005.

2. Armstrong, R. W.; Combs, A. P.; Tempest, P. A.; Brown, S. D.; Keating, T. A. Acc. Chem. Res. 1996, 29, 123-131. doi:10.1021/ar9502083

3. Dömling, A.; Ugi, I. Angew. Chem., Int. Ed. 2000, 39, 3168-3210. doi:10.1002/1521-3773(20000915)39:18<3168::AID-ANIE3168>3.0.CO ;2-U

4. Bienaymé, H.; Hulme, C.; Oddon, G.; Schmitt, P. Chem.-Eur. J. 2000, 6, 3321-3329.

doi:10.1002/1521-3765(20000915)6:18<3321::AID-CHEM3321>3.0.C O;2-A

5. Ugi, l.; Werner, B.; Dömling, A. Molecules 2003, 8, 53-66. doi:10.3390/80100053

6. Dömling, A. Chem. Rev. 2006, 106, 17-89. doi:10.1021/cr0505728

7. El Kaim, L.; Grimaud, L. Tetrahedron 2009, 65, 2153-2171. doi:10.1016/j.tet.2008.12.002

8. El Kaïm, L.; Grimaud, L.; Miranda, L. D.; Vieu, E. Tetrahedron Lett. 2006, 47, 8259-8261. doi:10.1016/j.tetlet.2006.09.123

9. Gámez-Montaño, R.; Ibarra-Rivera, T.; El Kaïm, L.; Miranda, L. D. Synthesis 2010, 1285-1290. doi:10.1055/s-0029-1218700

10. El Kaïm, L.; Grimaud, L.; Miranda, L. D.; Vieu, E.; Cano-Herrera, M. A.; Perez-Labrada, K. Chem. Commun. 2010, 46, 2489-2491. doi:10.1039/b924207d

11. El Kaïm, L.; Grimaud, L.; Vieu, E. Org. Lett. 2007, 9, 4171-4173. doi:10.1021/ol701678d

12. El Kaim, L.; Grimaud, L.; Legoff, X.; Azarte, M. M.; Miranda, L. D. Chem. Commun. 2011, 47, 8145-8147. doi:10.1039/c1cc12236c

13. Dos Santos, A.; El Kaïm, L.; Grimaud, L.; Ronsseray, C. Eur. J. Org. Chem. 2011, 17, 3117-3121. doi:10.1002/ejoc.201100261

14. Ugi, I.; Bodesheim, F. Chem. Ber. 1961, 94, 2797-2801. doi:10.1002/cber.19610941031

15. Ugi, I.; Bodesheim, F. Justus Liebigs Ann. Chem. 1963, 666, 61-64. doi:10.1002/jlac.19636660108

16. Zinner, G.; Kliegel, W. Arch. Pharm. 1966, 299, 746-756. doi:10.1002/ardp.19662990903
17. Zinner, G.; Bock, W. Arch. Pharm. 1971, 304, 933-943. doi:10.1002/ardp.19713041212

18. Failli, A.; Nelson, V.; Immer, H.; Götz, M. Can. J. Chem. 1973, 51, 2769-2775. doi:10.1139/v73-414

19. Marcaccini, S.; Pepino, R.; Polo, C.; Pozo, M. C. Synthesis 2001, 85-88. doi:10.1055/s-2001-9745

20. Marcos, C. F.; Marcaccini, S.; Pepino, R.; Polo, C.; Torroba, T. Synthesis 2003, 691-694. doi:10.1055/s-2003-38071

21. Sañudo, M.; Marcaccini, S.; Basurto, S.; Torroba, T. J. Org. Chem. 2006, 71, 4578-4584. doi:10.1021/jo060434y

22. Krasavin, M.; Bushkova, E.; Parchinsky, V.; Shumsky, A. Synthesis 2010, 933-942. doi:10.1055/s-0029-1219274

23. Krasavin, M.; Parchinsky, V.; Shumsky, A.; Konstantinov, I.; Vantskul, A. Tetrahedron Lett. 2010, 51, 1367-1370. doi:10.1016/j.tetlet.2009.12.141

24. Le Fevre, G.; Sinbandhit, S.; Hamelin, J. Tetrahedron 1979, 35 , 1821-1824. doi:10.1016/0040-4020(79)80005-8

25. Fouchet, B.; Joucla, M.; Hamelin, J. Tetrahedron Lett. 1981, 22, 1333-1336. doi:10.1016/S0040-4039(01)90310-7

26. Shimizu, T.; Hayashi, Y.; Miki, M.; Teramura, K. J. Org. Chem. 1987, 52, 2277-2285. doi:10.1021/jo00387a031

27. Yamashita, Y.; Kobayashi, S. J. Am. Chem. Soc. 2004, 126, 11279-22282. doi:10.1021/ja049498I

28. Frank, E.; Kardos, Z.; Wölfling, J.; Schneider, G. Synlett 2007, 1311-1313. doi:10.1055/s-2007-977452

29. Gergely, J.; Morgan, J. B.; Overman, L. E. J. Org. Chem. 2006, 71, 9144-9152. doi:10.1021/jo061537j

30. Ciesielski, M.; Pufky, D.; Döring, M. Tetrahedron 2005, 61, 5942-5947. doi:10.1016/j.tet.2005.01.111

For an oxidation of hydrazones induced by copper(II) salts.

31. Kabalka, G. W.; Guchhait, S. K. Org. Lett. 2003, 5, 4129-4131. doi:10.1021/ol035544v

For an oxidation of hydrazines induced by copper(II) salts.

\section{License and Terms}

This is an Open Access article under the terms of the Creative Commons Attribution License

(http://creativecommons.org/licenses/by/2.0), which permits unrestricted use, distribution, and reproduction in any medium, provided the original work is properly cited.

The license is subject to the Beilstein Journal of Organic Chemistry terms and conditions:

(http://www.beilstein-journals.org/bjoc)

The definitive version of this article is the electronic one which can be found at: $\underline{\text { doi: } 10.3762 / \text { bjoc. } 7.153}$ 